\title{
Does tethering of mobile prey measure relative predation potential? An empirical test using mummichogs and grass shrimp
}

\author{
R. T. Kneib*, C. E. H. Scheele** \\ University of Georgia Marine Institute, Sapelo Island, Georgia 31327, USA
}

\begin{abstract}
Tethering prey organisms continues to be a popular method of evaluating spatial and temporal variation of predator effects on population or community dynamics in marine environments. However, this technique relies on an untested fundamental assumption that there is a simple, reliable relationship between losses of tethered prey and site-specific risk of mortality due to predation. To test this, we placed tethered and free grass shrimp Palaemonetes pugio together in mesocosms ( $1.3 \mathrm{~m}$ diameter) and varied the level of predation potential by exposing the prey to different densities of the mummichog Fundulus heteroclitus, a common predatory fish in salt marshes of the eastern US. There were 10 replicate experimental runs, each involving 6 mesocosms that included 3 tethered and 27 free shrimp and either $0,1,2,4,8$, or 16 predators. Survival of tethered shrimp was assessed after 15, 30, 45, 60, 90, 120 and $180 \mathrm{~min}$, but survival of free shrimp was determined only at the end of each run (180 $\mathrm{min})$. In the absence of predators, average survival of tethered $(93.3 \%)$ and free $(99.3 \%)$ shrimp was similar. At the highest predator density, none of the tethered shrimp survived to $180 \mathrm{~min}$, while survival in the free group was $85.1 \%$. A significant interaction (ANOVA, $F_{5,108}=11.88, p<0.0001$ ) between tether treatment and predator density indicated a difference in the slopes of the relationships describing survival of free and tethered prey across the experimental gradient of predation potential. Chronological analysis of tethered prey losses across the experimental predation gradient also detected significant interactions (repeated-measures ANOVA, $F_{30,324}=3.24, \mathrm{p}<0.001$ ) between the effects of predator density and exposure time. Tethering grass shrimp as a means of assessing even relative effects of predation by mummichogs on free prey is of questionable value because the relationship between relative loss rates of tethered and free shrimp changed across a gradient of predation potential and varied with exposure time.
\end{abstract}

KEY WORDS: Estuaries · Fundulus · Palaemonetes · Predator-prey interactions · Sapelo Island

\section{INTRODUCTION}

Predators usually play a pivotal role in the organization of natural communities and several experimental and observational techniques have been applied to measure or estimate their effects. One particularly controversial method used in marine systems for the past 2 decades is tethering (for examples, see Peterson \& Black 1994, Aronson \& Heck 1995, McGuinness 1997). The technique usually involves attaching live prey to the substratum with short ( $\leq 1 \mathrm{~m}$ ) lengths of line (often

\footnotetext{
"E-mail: rtkneib@arches.uga.edu

- Present address: 4814 Bayfield Terrace, Madison, Wiscon$\sin 53705$, USA
}

nylon monofilament) or wire for a predetermined time (usually 12 to $24 \mathrm{~h}$ ) and using the proportion of individuals missing from the tethers as a quantitative measure of predation. Sometimes these data are supplemented with information on individual prey survival times gathered by checking for losses at shorter time intervals (e.g. Shulman 1985) or by using chronographic devices (e.g. Minello 1993, Haywood \& Pendrey 1996) or video cameras (e.g. Wahle \& Steneck 1992, Heck \& Valentine 1995) to record predation events remotely.

Prey taxa used in tethering experiments exhibit a range of locomotor capacities, and have included a variety of crabs (Heck \& Thoman 1981, Wilson 1989, Beck 1995), lobsters (Herrnkind \& Butler 1986, Wahle \& Steneck 1992), fishes (Shulman 1985, McIvor \& 
Odum 1988), brittle stars (Aronson 1989), shrimps (Minello 1993, Haywood \& Pendrey 1996), sea urchins (McClanahan \& Shafir 1990, Heck \& Valentine 1995), scallops (Peterson et al. 1989, Arsenault \& Himmelman 1996), and clams (Micheli 1996). Biases associated with the preferential selection of tethered prey by predators are widely acknowledged, and several studies have demonstrated that tethering of mobile prey increases their susceptibility to predators by reducing the effectiveness of their escape response (e.g. Barbeau \& Scheibling 1994, Zimmer-Faust et al. 1994, Smith 1995) or by otherwise altering the behavior of the prey making them more susceptible to predators under certain conditions (e.g. Barshaw \& Able 1990, Curran \& Able 1998).

Zimmer-Faust et al. (1994) noted that a significant correlation between relative and natural absolute rates of predation has never been demonstrated for any species. Studies that have compared mortality of tethered and free prey under controlled conditions usually have done so only at a single level of predation (e.g. Heck \& Thoman 1981, Barbeau \& Scheibling 1994, Smith 1995, Curran \& Able 1998). Even though a variety of artifacts have been associated with the approach, and empirical tests of the basic underlying assumption are lacking, tethering of mobile prey continues to be widely used in assessing the effects of predators in marine systems.

Peterson \& Black (1994) focused on tethering studies to exemplify the general consequences of failing to recognize 'artifacts of intervention' in ecological experiments. Their principal concern was that the magnitude of effects associated with experimental artifacts might not be additive, but instead would co-vary with treatment level. In a response to the critique, Aronson \& Heck (1995) defended the tethering approach by challenging the accuracy of certain statements presented in Peterson \& Black (1994). While acknowledging the principal criticism raise by Peterson \& Black (1994), Aronson \& Heck (1995) expressed the opinion that the existing body of literature on tethering included sufficient experimental rigor and appropriate attention to effects of potential artifacts so that the general conclusions are valid.

Proponents of tethering rarely claim that losses of tethered prey measure any type of absolute mortality rate, but contend that they are a relative measure of. spatial and/or temporal variation in the effect of predators on prey populations (e.g. Heck \& Wilson 1987). Results of tethering studies are invariably subjected to statistical analysis, so proportional loss of prey from tethers must be considered a statistic estimating a parameter associated with the effect of predators at some site or time. The identity of the estimated parameter seems to vary among tethering studies. Most have considered proportional iosses of prey from teth- ers as reflective of differences in either 'predation rates', 'predation pressure', 'predation risk', 'predation potential' or 'predation intensity', often using some or all of these terms interchangeably and without explicit definitions when presenting the findings (e.g. Wilson 1989, Minello 1993, Bologna \& Heck 1999). Others have used tethering with the intention of measuring relative 'predator encounter rates' (e.g. Shulman 1985, McIvor \& Odum 1988), or to test 'vulnerability to predators' (Arsenault \& Himmelman 1996). Unless one takes the position that all of these terms are equivalent, or that each differs from the others by some constant factor, there seems to be no consensus regarding the parameter being estimated by tether losses.

One of the most explicit definitions of the metric estimated by tethering was given by Aronson \& Heck (1995), who presented the view that tether losses measure 'predation potential', defined by Aronson (1989) as 'the rate at which the prey of interest would be consumed were they readily available to predators.' Aronson (1989) made a distinction between predation potential and 'predation pressure', which was defined as 'the natural frequency of predatory attacks.' While these are by. no means universally accepted definitions - for example, Lincoln et al. (1982) defined predation pressure more broadly as 'the effects of predation on the dynamics of a prey population' - the study by Aronson \& Heck (1995) was one of the few published on the topic of tethering to provide any explicit definition of parameters that were (i.e. predation potential) and were not (i.e. predation pressure) measured by tethering. Consequently, we used their definition in designing an empirical test of the tethering technique. In this study, we tested the hypothesis that proportional losses of tethered prey are a relative measure of mortality experienced by free prey across a gradient of predation potential.

\section{MATERIALS AND METHODS}

Mesocosms. The experiment was conducted outdoors at the University of Georgia Marine Institute on Sapelo Island, Georgia (USA), during July and August 1998. All experimental manipulations occurred in a set of 6 circular tanks $(1.3 \mathrm{~m}$ diameter, $0.25 \mathrm{~m}$ deep $)$ arranged in 2 rows at ground level. A layer of clean beach sand ( $2 \mathrm{~cm}$ deep) covered the bottom of each tank, and an opaque plastic tarpaulin suspended $2 \mathrm{~m}$ above the tanks provided shade from direct insolation. During experimental runs, estuarine water pumped from South End.Creek flowed continuously into each tank and drained from adjustable stand-pipes that maintained water depth at 13 to $15 \mathrm{~cm}$. A thermistor (Model ES-060, Omnidata International, Inc.) installed 
in one of the tanks was attached to an electronic datalogger (Easy Logger Model EL-824, Omnidata International, Inc.) that measured water temperature at $10 \mathrm{~min}$ intervals and recorded the hourly averages. Between experimental runs, tanks were drained and rinsed with freshwater.

Experimental subjects and design. We chose adult daggerblade grass shrimp Palaemonetes pugio (Crustacea: Palaemonidae) as the prey species and mummichogs Fundulus heteroclitus (Pisces: Cyprinodontidae) as the predator in this experiment because these are among the most abundant and hardy nekton in tidalmarsh estuaries of the eastern US (Kneib 1997). Estimated low-tide densities of mummichogs in marsh creeks and embayments have ranged from 0.7 to 11 ind. $\mathrm{m}^{-2}$ (Nixon \& Oviatt 1973, Valiela et al. 1977, Meredith $\&$ Lotrich 1979), and grass shrimp commonly occur at densities from 2 to $>200$ ind. $\mathrm{m}^{-2}$, usually averaging $>10$ ind. $\mathrm{m}^{-2}$ (Wood 1967, Nixon \& Oviatt 1973, Sikora 1977).

Grass shrimp (25 to $35 \mathrm{~mm}$ total length, TL) were collected with dip nets and cast nets from South End Creek and held for $<24 \mathrm{~h}$ in $76 \mathrm{l}$ aquaria prior to each experimental run. Cylindrical minnow traps (Cuba Specialty Manufacturing Co.) were used to collect mummichogs ( 70 to $100 \mathrm{~mm}$ TL) from several local tidal creeks and ditches. Only female mummichogs were used in order to reduce the possibility of intraspecific behavioral interactions (e.g. mating and associated agonistic interactions among males) that might have confounded the experimental responses. Mummichogs in the appropriate size class were not always abundant when needed, so they were routinely collected and held in $76 \mathrm{l}$ aquaria for up to 2 wk. Captive mummichogs were fed a daily ration of commercial fish food (Shrimp-el-etts ${ }^{\circledR}$, Hartz Mountain Co.), but were starved for ca $15 \mathrm{~h}$ before each experimental run. Individual predators were used in up to 2 experimental trials; potential prey individuals were used only once.

Before beginning an experimental trial, 3 tethered and 27 free shrimp were added to each tank (equivalent to a total prey density of 22.6 ind. $\mathrm{m}^{-2}$ ). Free shrimp were included to simulate conditions that should be encountered in field trials, where free prey would likely be a more abundant alternative to tethered individuals. Tethers were $30 \mathrm{~cm}$ long and consisted of monofilament line (Stren ${ }^{2}$ Clear/Blue Fluorescent, 2 lb test) that was attached to the mid-dorsal surface of the shrimp's cephalothorax with a small drop of cyanoacrylate glue (Krazy Glue ${ }^{\circledast}$ gel). The other end of the line was tied to a small (ca 25 to $30 \mathrm{~cm}^{2}$ ) shard of terracotta tile that was inserted into the sand until it was flush with the surface substratum. Both tethered and free shrimp were introduced to the experimental tanks at least $15 \mathrm{~h}$ prior to each trial. Shrimp that died, and any tethered shrimp that molted, during this acclimation period were replaced.

To initiate an experimental trial, each tank received either $0,1,2,4,8$, or 16 mummichogs, corresponding to predator densities of $0,0.75,1.5,3.0,6.0,12.0$ ind. $\mathrm{m}^{-2}$, respectively. Ten independent trials (replicates) of the complete experiment were conducted during July to August 1998. The level of predator density treatment assigned to each tank was randomly determined at the start of every trial. Survival of tethered shrimp was assessed at $15,30,45,60,90,120$, and $180 \mathrm{~min}$. At the end of each trial (180 $\mathrm{min})$, all predators and prey were removed from the pools and the numbers of surviving shrimp (both tethered and free) were counted. In addition, all tethered shrimp were measured before and after each trial, and a subset of 15 free shrimp from each pool was measured at the end of every trial.

Response variables and statistical analyses. The principal response variable in this experiment was proportion of shrimp surviving. An improved angular transformation (arcsin $\sqrt{ }[(x+0.375) /(n+0.75)]$, where $x=$ number surviving and $n=$ the initial number) was applied to proportional survival data to induce normality and variance homogeneity prior to statistical analysis (Zar 1996, Sokal \& Rohlf 1997). The effect of predator density on survival of free shrimp was determined only at the maximum exposure time (180 min) because it was impractical to assess the survival of this group during experimental trials. Effects of predator density (6 levels), tether treatment ( 2 levels) and the potential interaction between these factors were tested in a 2-way analysis of variance (ANOVA) applied to the transformed survival data using a factorial design with 10 replicates of each treatment combination.

The experimental design allowed additional analysis of temporal responses in survival of tethered shrimp across a gradient of predation potential. Here we used a repeated-measures ANOVA because survival was measured at different times within an experimental trial in the same groups of shrimp. The Huynh-Feldt statistic was used to test the assumption of compound symmetry or sphericity (Zar 1996). The probability associated with this statistic never differed substantially from that associated with the $F$-statistic in our univariate repeated-measures analyses, which indicated conformity to the required assumption of sphericity. Unlike some repeated-measures designs, ours included independent replicates (trials), which allowed us to test the interaction between predator density and exposure time. Effects of exposure time and its interaction with predator density were assessed within subjects (tanks).

We used a 1-way ANOVA to compare the size of predators and the total number of shrimp consumed 
across levels of the predator density treatment. If appropriate, Tukey's test was used to perform a posteriori multiple comparisons (experiment-wise $\alpha=0.05$ ) to determine which groups of means differed from one another when ANOVA detected a significant difference among groups (Zar 1996). Paired $t$-tests were used to compare mean sizes of live tethered shrimp before and after exposure to predators, and mean sizes of tethered and free shrimp used in the experiment. In testing for differences between the sizes of tethered and free shrimp, we compared the mean size of tethered shrimp within a tank at the start of an experimental trial with that of free shrimp from the same tank measured at the end of the trial. This was necessary because too few of the tethered shrimp remained at the end of each trial, which was the only time free shrimp were measured. All statistical analyses of the data were performed using version 8.02 of the computer software package SYSTAT ${ }^{\circledR}$ (SPSS Inc.).

\section{RESULTS}

\section{Physical environmental conditions}

Average daily water temperature varied within the range 26.9 to $30.3^{\circ} \mathrm{C}$ during the study period (Fig. 1). Water temperature in the mesocosms never fell below $25.4^{\circ} \mathrm{C}$ nor rose above $34.2^{\circ} \mathrm{C}$ during any experimental trial. The minimum and maximum average temperatures during experiment occurred in Trials 6 $\left(27.7^{\circ} \mathrm{C}\right)$ and $4\left(30.3^{\circ} \mathrm{C}\right)$, respectively. Salinity in the estuary at the time of the experiment was in the range 22.9 to $33.0 \mathrm{ppt}$ and averaged $27.9 \mathrm{ppt}$ (University of Georgia Monitoring Station at Marsh Landing, JulyAugust 1998).

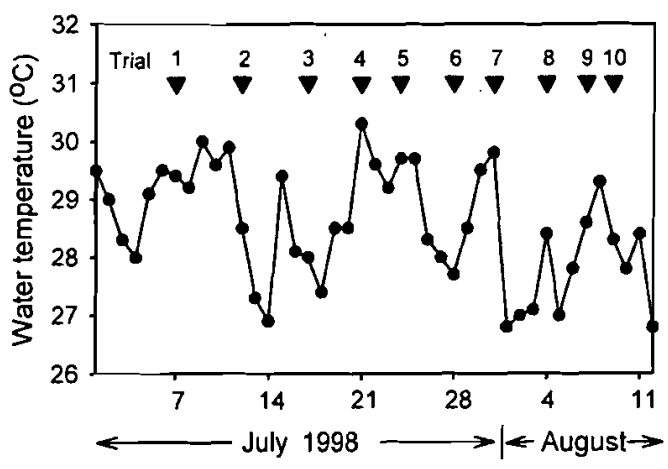

Fig. 1. Temporal variation in daily mean water temperature and distribution of experimental trials

\section{Prey and predator sizes}

Mean TLs of tethered (28. 1 mm TL) and free $(27.8 \mathrm{~mm}=-\ldots$ TL) prey used in the experiment did not differ significantly (paired $t$-test, $t_{59}=1.5, \mathrm{p}=0.2$ ), nor was there a significant difference in mean prey sizes among the predator density treatments (1-way ANOVA, $F_{5,54}=$ $0.467, \mathrm{p}=0.799$ ). However, there was a statistically detectable difference in predator size among treatment levels (1-way ANOVA, $F_{4,45}=4.28, \mathrm{p}=0.005$ ). Mean TL of mummichogs at the lowest predator density was 3 to $6 \%$ larger than at higher densities (Table 1). Post hoc multiple comparisons (Tukey's HSD test, $\alpha=0.05$ ) detected that the mean size of predators at the lowest experimental density $\left(0.75\right.$ ind. $\left.\mathrm{m}^{-2}\right)$ differed from those at the 3 highest densities $(3,6$ and 12 ind. $\mathrm{m}^{-2}$ ); no other group means differed significantly. Although large mummichogs ( $\geq 90 \mathrm{~mm}$ TL) were used at every density treatment level, the addition of smaller individuals ( 70 to $75 \mathrm{~mm} \mathrm{TL}$ ) to the predator pool tended to reduce the overall mean size in tanks with more than 1 or 2 predators (Table 1 ).

\section{Survival of tethered and free prey}

Similar numbers of tethered and free prey were consumed in the experiment but because the density (availability) of free prey was $9 \times$ greater than that of tethered prey, the relative mortality of tethered prey was much greater (Table 2). This demonstrated that tethered prey were consumed preferentially by mummichogs. Analysis of the prey survival data from the end of the experiment (180 min duration) detected not only the expected differences due to predator density and tether treatments, but also revealed a highly significant interaction between treatments (Table 3). Although the rank order of predator effects seemed to be preserved (i.e. a doubling of predator density usually resulted in reduced survival), the relative survival rates of tethered and free 
Table 2. Results of paired $t$-tests (within tanks) comparing the number of tethered and free prey consumed and the proportional survival of each group. Experimental tanks without predators (predator density $=0$ ) were excluded from the analyses. Proportional data were analyzed after applying an improved angular transformation (see 'Materials and methods')

\begin{tabular}{|lccccc|}
\hline & Tethered & Free & $t$-value & df & $\mathrm{p}$ \\
\hline Mean ( $\pm \mathrm{SD}$ ) no. & 2.4 & 1.9 & 0.94 & 49 & 0.352 \\
of prey consumed & \pm 1.05 & \pm 3.31 & & & \\
$\begin{array}{l}\text { Mean ( } \pm \text { SD) transformed } \\
\text { proportion of prey sur- }\end{array}$ & 0.519 & 1.314 & -16.76 & 49 & $<0.001$ \\
viving (in radians) & \pm 0.3207 & \pm 0.1684 & & & \\
\hline
\end{tabular}

differences in mean survival among the 6 levels of the predator density treatment (Table 4). For free shrimp, the only statistically detectable difference was between the highest level of predation used in the experiment (12 predators $\mathrm{m}^{-2}$ ) and no predators; survival in the groups actually exposed to predators could not be distinguished. The results were similar for tethered shrimp, except that the proportion of prey surviving at a low predator density $(0.75$ predators $\mathrm{m}^{-2}$ )-though indistinguishable from that in the absence of predators - was

Table 3. Results of a 2-way ANOVA comparing the effects of predator density $\left(0,0.75,1.5,3.0,6.0\right.$ and 12 ind. $\left.\mathrm{m}^{-2}\right)$ and tether treatment (tethered vs free prey) on the proportion of prey surviving after $180 \mathrm{~min}$. An improved angular transformation was applied to the survival data prior to analysis

\begin{tabular}{|lcrrc|}
\hline Source of variation & df & \multicolumn{1}{c}{ MS } & $F$-ratio & p \\
\hline Predator density & 5 & 0.9075 & 24.99 & $<0.0001$ \\
Tether treatment & 1 & 14.8764 & 409.60 & $<0.0001$ \\
Predator $\times$ Tether & 5 & 0.4316 & 11.88 & $<0.0001$ \\
Residual (error term) & 108 & 0.0363 & & \\
Total & 119 & & & \\
\hline
\end{tabular}

shrimp differed across the gradient of predation potential (Fig. 2).

One-way ANOVA performed on survival data from each level of the tether treatment separately provided some additional insight into the resolution of differences one might expect to achieve when using loss rates as a measure of predation potential. The overall effect of predator density on survival was significant in both the tethered $\left(F_{5,54}=25.70, \mathrm{p}<0.001\right)$ and free $\left(F_{5,54}=2.58, \mathrm{p}=0.036\right)$ prey groups. However, post hoc multiple comparison tests could resolve few significant

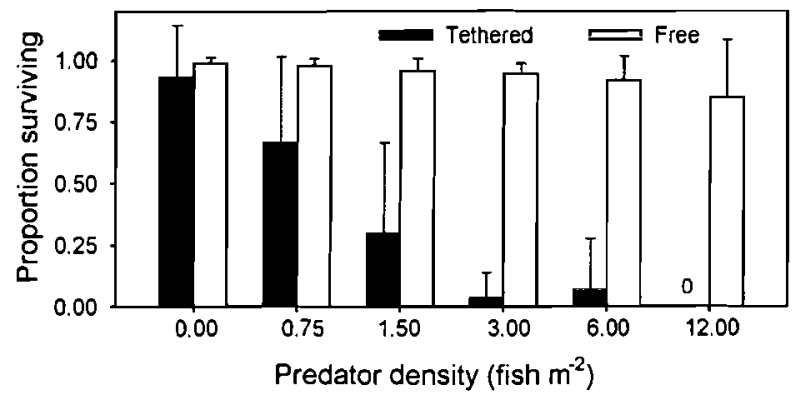

Fig. 2. Palaemonetes pugio. Final survivorship of tethered and free prey along the experimental gradient of predation potential after $180 \mathrm{~min}$. Each point is the untransformed mean $(+\mathrm{SD})$ of 10 replicates and represents the average survival of 30 tethered or 270 free prey individuals significantly greater than at higher levels of predation potential. Tukey's HSD test was unable to distinguish any differences among levels of predation potential associated with 1.5 to 12 predators $\mathrm{m}^{-2}$.

Table 4. Results of post hoc Tukey HSD multiple comparison tests on the proportion of tethered and free shrimp surviving at each of the experimental levels of predator density. Analyses were conducted on transformed data but values are given as actual proportions surviving to the end of the experiment (180 $\mathrm{min}) ;$ groups sharing a common underline do not differ significantly $(\alpha=0.05)$

\begin{tabular}{|lccccccc|}
\hline & \multicolumn{6}{c|}{ Predator density (ind. $\mathrm{m}^{-2}$ ) } \\
& 0 & 0.75 & 1.5 & 3.0 & 6.0 & 12.0 \\
\hline Tethered & $\underline{0.93}$ & 0.67 & $\underline{0.30}$ & 0.03 & 0.07 & 0.00 \\
Free & $\underline{0.99}$ & 0.98 & 0.96 & 0.94 & 0.92 & 0.85 \\
\hline
\end{tabular}

\section{Effect of predator density and exposure time on prey survival}

Using data collected at predetermined intervals during each trial we plotted a family of survivorship curves that show the effect of exposure time on survival of tethered prey across the experimental gradient of predation potential (Fig. 3), Repeated-measures ANOVA performed on the transformed data detected a highly significant interaction between the effect of predator density and time on prey survival (Table 5). The interaction was manifested in the changing shape (i.e. slope) of the survivorship curve across the predation gradient at different exposure times. As early as $15 \mathrm{~min}$ into the experiment, the tethered prey had already experienced substantial mortality at most levels of predator density, except that loss rates at the highest predator densities seemed to lag those at lower densities. At all exposure times, the slope of the survivorship curve was steepest at predator densities 


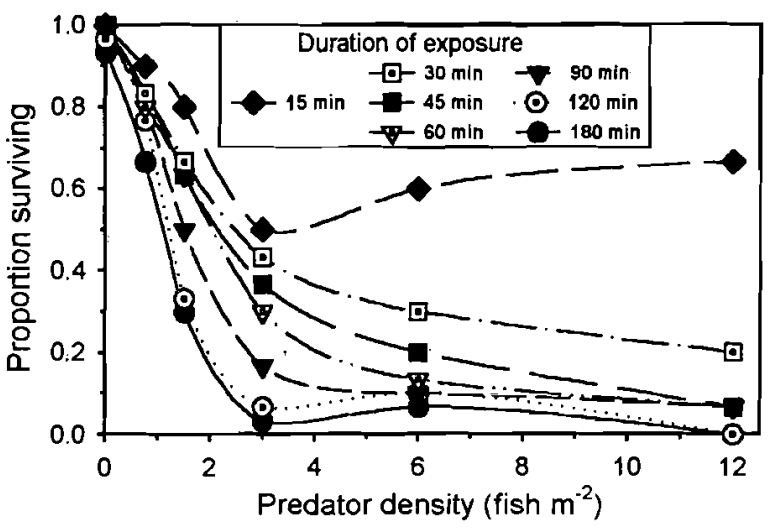

Fig. 3. Palaemonetes pugio. Family of curves describing temporal changes in the mean survivorship of tethered prey across an experimental gradient of predation potential. Each point represents 10 replicates ( 30 shrimp) $\ldots=$

below 3 ind. $\mathrm{m}^{-2}$; above that density, the incremental change in prey survival along the gradient of predation potential seemed to approach that of free prey, even at $15 \mathrm{~min}$ when tethered prey had not yet been depleted (Fig. 3).

\section{Potential effects of interactions among predators}

Although most of the total available prey (tethered + free) remained at the end of the experiment, per capita consumption of prey tended to decrease as the number of predators increased (Table 6), suggesting a decline in predator efficiency with density. Statistically significant differences in per capita consumption along the gradient of predation potential occurred only for tethered prey, in which groups of means above and below a density of 3 predators $\mathrm{m}^{-2}$ could be distinguished by the post hoc multiple comparison test (Tukey's HSD). This is the same point at which the survivorship curves for tethered prey sharply changed slope, as this prey type was effectively depleted. There was no evidence of a compensatory increase in per capita consumption of free prey after the more susceptible tethered prey were consumed (i.e. above 3 predators $\mathrm{m}^{-2}$ ), even though free prey remained abundant in the mesocosms. At the lowest predator density $(1$ predator mesocosm $\mathrm{m}^{-1}$ ), per capita consumption was 1.6 prey (tethered + free) after $180 \mathrm{~min}$. If this consumption rate was maintained across the gradient of predation potential, we would have expected only 1 or 2 prey to survive ( 3.3 to $6.6 \%$ survival) at the highest predator density (16 predators mesocosm $\left.{ }^{-1}\right)$, but instead observed $76.7 \%$ survival $(0 \%$ tethered, $85.2 \%$ free) at this treatment level. More than half of the mortality that occurred among free prey at the highest predator
Table 5. Results of repeated-measures ANOVA to test for the effects of predator density, time and the interaction between these factors on survival of tethered prey. The proportion of prey surviving at $15,30,45,60,90,120$ and 180 min within a tank was the repeated measure, and was transformed by an improved angular transformation prior to analysis

\begin{tabular}{|lrrrr|}
\hline Source of variation & df & MS & $F$ & $\mathrm{p}$ \\
\hline Between subjects & & & & \\
$\quad$ Predator density & 5 & 6.9829 & 26.76 & $<0.001$ \\
$\quad$ Error & 54 & 0.2610 & & \\
Within subjects & & & & \\
$\quad$ Time & 6 & 0.9598 & 36.39 & $<0.001$ \\
Time $\times$ Predator density & 30 & 0.0855 & 3.24 & $<0.001$ \\
Error & 324 & 0.0264 & & \\
Total & 419 & & & \\
\hline
\end{tabular}

Table 6. Results of 1-way ANOVA testing the effect of predator density on per capita consumption of tethered and free prey after $180 \mathrm{~min}$. Group means $(n=10)$ that did not differ significantly (Tukey's HSD test, $\alpha=0.05$ ) share a common underline

\begin{tabular}{|lcccccc}
\hline & \multicolumn{7}{c}{ Predator density (ind. $\mathrm{m}^{-2}$ ) } \\
Summary of 1-way & 0.75 & 1.5 & 3.0 & 6.0 & 12.0 \\
\hline Tethered prey & & & & & & \\
$F_{4,45}=5.18, \mathrm{p}<0.002$ & 1.0 & 1.05 & $\underline{0.72}$ & 0.35 & 0.19 \\
$\begin{array}{l}\text { Free prey } \\
F_{4,45}=0.72, p=0.585\end{array}$ & $\underline{0.60}$ & 0.50 & 0.38 & 0.26 & 0.26 \\
\hline
\end{tabular}

density was attributable to a single experimental trial (Trial 7) in which 21 of the 27 free prey were consumed. If that trial is excluded as an outlier, survival of free prey at the highest predator density was $96.3 \%$ (n $=9$ ) and the average overall survival of free prey across the gradient of predation potential was $94.1 \%(n=45)$.

\section{DISCUSSION}

Peterson \& Black (1994) pointed out that a fundamental, and usually untested, assumption in tethering experiments is that any biases associated with tethering prey remain constant across treatments levels. The criticism has been widely interpreted as meaning that the effect of the tether on the susceptibility to predation may vary across habitat types (e.g. Barshaw \& Able 1990), predator species (e.g. Barbeau \& Scheibling 1994) or prey species (e.g. Curran \& Able 1998). While these and other studies (e.g. Zimmer-Faust et al. 1994) have provided insights into the mechanisms responsible for the widely acknowledged differences in susceptibility to predation between tethered and free prey, they have not addressed the more basic 
issue of what tether losses actually measure. The present study provided an empirical test of the hypothesis that the proportional losses of tethered prey reflected the proportional losses of free prey along a gradient of predation potential (i.e. tether losses are a relative measure of actual predation potential). We created an experimental gradient of predation potential (sensu Aronson 1989) by manipulating predator density in mesocosms that contained no structural refuge for the prey. Consequently, both tethered and free prey were equally 'available' to the predators. Free prey were many times more abundant than tethered individuals in our experiment, as might be expected under field conditions. We did not require that absolute mortality rates of tethered and free prey be equivalent because the expectation from findings of previous studies was that losses would be greater for tethered than free prey (e.g. Barbeau \& Scheibling 1994, Zimmer-Faust et al. 1994). However, for the fundamental assumption of the tethering approach to be true, the relative rate at which losses occur across a gradient of predation potential must be similar for both tethered and free prey (i.e. the slopes of the lines describing losses across the predation gradient should be the same). Results of our experiment demonstrated that the assumption was false (Table 3). Not only was the absolute loss rate of tethered prey greater than that of free prey, but the relative loss rates of the 2 prey groups diverged across the predation gradient (Fig. 2).

The family of survivorship curves relating exposure time to survival of tethered prey (Fig. 3) showed that the relationship between proportional survival within this prey group also varied temporally across the gradient of predation potential. We suspect that a reduction in predator efficiency and depletion of tethered prey with increasing predator density both contributed to shaping the survivorship curves. Survival of tethered prey fell more sharply at lower predator densities, and there was a time lag in the expected response of survival at higher levels of predator density (i.e. more tethered shrimp survived predator densities above than below 3 ind. $\mathrm{m}^{-2}$ after $15 \mathrm{~min}$ ). Both observations are consistent with a density-dependent effect on predator efficiency. For tethered prey, one could argue that the reduction in mortality with increasing predator density was a simple function of prey limitation. For example, at a density of 1 predator mesocosm ${ }^{-1}(0.75$ predators $\mathrm{m}^{-2}$ ) an average of 1 tethered shrimp was consumed by the end of the experiment. If per capita consumption of prey was constant, we would expect all of the tethered shrimp ( 3 ind. mesocosm ${ }^{-1}$ ) to be consumed by the end of the experiment at a predator density of about 2.25 ind. $\mathrm{m}^{-2}\left(<3\right.$ ind. $\left.\mathrm{m}^{-2}\right)$. Fewer than $7 \%$ of the tethered prey survived the experiment at predator densities $>3$ ind. $\mathrm{m}^{-2}$, so this seems a reasonable explanation. However, the early (15 min exposure time, Fig. 3) lag in response of tethered prey survival at high predator densities tends to support the hypothesis of density-dependent predation efficiency. Per capita consumption of free prey also seemed to decline with predator density, though no statistically significant differences were detected among treatment levels (Table 6). When the preferred tethered prey were depleted (at densities $\geq 3$ predators $\mathrm{m}^{-2}$ ), there was no evidence of an increase in consumption of free prey. Density-dependent reductions in per capita consumption rates also have been observed for other predators, including blue crabs Callinectes sapidus when feeding on hard clams (Mansour \& Lipcius 1991) and smaller conspecifics (Moksnes et al. 1997). One consequence for the present study is that the experimental gradient in predation potential may not have been a linear function of predator density. However, the principal conclusion that the relative survival rates of free and tethered prey differed across the gradient is robust in the face of this potential non-linearity because both free and tethered prey were exposed to the same gradient in predation potential.

Differential responses of predators to tethered and free prey groups across habitats or time is at the core of the problem with the tethering technique and can be demonstrated graphically by comparing the proportional loss rates of tethered and free prey across intervals of predation potential (Fig. 4). Each interval (e.g. 0.75 to 1.5 fish $\mathrm{m}^{-2}, 1.5$ to 3.0 fish $\mathrm{m}^{-2}$, etc.) along the experimental gradient of predation potential represents a doubling of predator density (pd) experienced by both tethered (tet) and free prey groups. If losses of tethered prey accurately reflect the relative losses of

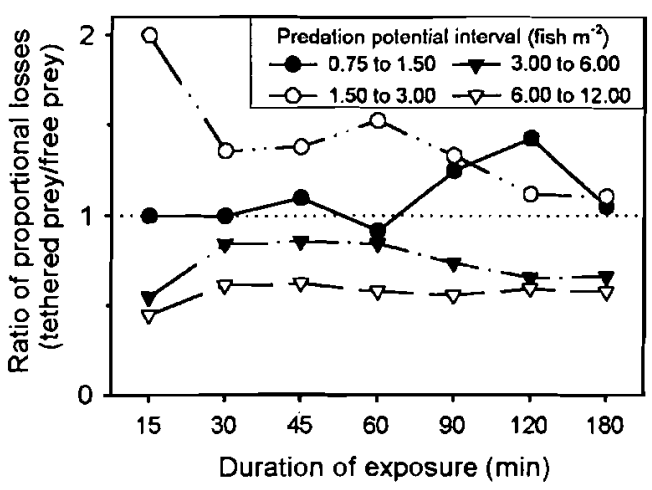

Fig. 4. Palaemonetes pugio. Ratios of relative losses of tethered prey (after 15 to $180 \mathrm{~min}$ exposure to predators) to relative losses of free prey (after $180 \mathrm{~min}$ ) from adjacent intervals along the experimental gradient of predation potential. Values falling along the dotted reference line (ratio $=1$ ) identify combinations of times and predator densities when relative losses of tethered prey equaled those of free prey. Relative losses of tethered prey overestimate relative losses of free prey above the line and underestimate them below the line 
free prey, the ratio of the proportions of tethered prey consumed between levels of predation potential $\left[R_{\mathrm{tet}}=\right.$ $\left.\left(C_{\mathrm{tel}} / 30\right)_{2 \mathrm{pd}} /\left(C_{\mathrm{tet}} / 30\right)_{\mathrm{pd}}\right]$ should equal the ratio of the proportions of free prey consumed $\left[R_{\mathrm{free}}=\left(C_{\mathrm{free}} / 270\right)_{2 \mathrm{pd}} /\right.$ $\left(C_{\text {free }} / 270\right)_{\text {pd }}$ between those same levels (i.e. $R_{\text {tet }} / R_{\text {free }}=$ 1). We compared the ratio of the proportional losses of free prey after $180 \mathrm{~min}$ with that of tethered prey at different times during the experiment to address the issue of differential depletion of available prey in the tethered and free groups over time. Depletion of tethered prey during the experiment should have resulted in a loss rate from this prey group that decreased with time relative to that of the always abundant free prey (resulting in $R_{\text {tet }} / R_{\text {free }}<1$ ), which could make early proportional tether losses better predictors of relative losses in free prey. In fact, there was no consistent temporal pattern in the changing relationship between relative rates of loss in tethered and free prey groups along the gradient of predation potential (Fig. 4). In general, tether losses tended to overestimate $\left(R_{\mathrm{tet}} / R_{\text {free }}\right.$ $>1$ ) loss rates of free prey below predator densities of 3.0 ind. $\mathrm{m}^{-2}$ and underestimate $\left(R_{\text {tet }} / R_{\text {free }}<1\right)$ them at higher predator densities. Although proportional tether losses appeared to be a good predictor $\left(R_{\mathrm{tet}} / R_{\mathrm{free}}=1\right)$ of relative mortality for free prey along one portion of the predation gradient (between 0.75 and 1.50 predators $\mathrm{m}^{-2}$ ), the relationship held only for the first hour of the experiment. After $60 \mathrm{~min}$, tether losses in this portion of the predation gradient overestimated the relative mortality of free prey. At the end of the experiment $(180 \mathrm{~min})$, the ratio of relative loss rates again approached unity in this portion of the predation gradient, as well as in the next interval (1.5 and 3 predators $\mathrm{m}^{-2}$ ), but these instances of conformity were more likely due to the differential effect of tethered prey depletion on the ratio of loss rates rather than representing a relationship between the relative mortality of tethered and free prey.

Our simple experimental setting provided an arena free of the innumerable complexities that one could reasonably expect to encounter under field conditions. In a less controlled environment, any relationship between the relative losses of tethered and free prey would need to be more robust than required here in order to overcome even a subset of the behavioral permutations between predator and prey that might be generated by the presence of the tether. For example, in an experimental study of the effect of limb loss on survival of juvenile blue crabs Callinectes sapidus, Smith (1995) recognized that differential responses of adult crabs to tethered and free juveniles could easily lead to spurious conclusions. When exposed to cannibalistic adults, juvenile crabs with missing limbs had the same chance of survival as intact juveniles unless tethered. When the escape response was hampered by a tether, those with missing limbs were more likely to be killed than intact individuals. Survival data from tethered juveniles supported the conclusion that limb loss resulted in higher mortality when it actually had no measurable effect on survival of juveniles in normal encounters with larger conspecifics.

Tethering may be an appropriate method of monitoring natural loss rates of subjects incapable of selfdirected mobility as argued by McGuinness (1997), who did not find significant experimental artifacts associated with tethering mangrove propagules and leaves. However, unexpected effects associated with tethering also can occur in prey with a limited capacity for mobility. For example, Micheli (1996) compared the loss rates of tethered and free hard clams Mercenaria mercenaria from fenced and unfenced plots in intertidai and subtidal estuarine habilats and found that losses of free clams were greater than that of the tethered groups, especially in unfenced plots. Higher survival of tethered individuals contrasts with expectations based on previous tethering studies but it seemed likely in this case that tethers and fences acted to prevent mobile predators (probably blue crabs) from removing prey that they were unable to handle and consume in situ, perhaps because of tidally induced time constraints on foraging (e.g. Kneib 1995).

Chronology of losses can yield insights into the nature of predator-prey relationships pertinent to interpretation of results in both field and experimental situations involving tethered prey (e.g. Wahle \& Steneck 1992, Zimmer-Faust et al. 1994, Haywood \& Pendrey 1996). Under natural conditions, exposure times and predation intensities may vary because of speciesspecific differences in the behavior of both predators and prey that can be altered by the presence of a tether (e.g. Barshaw \& Able 1990, Barbeau \& Scheibling 1994, Curran \& Able 1998). Many predators are highly mobile and may be either resident or transient with respect to the location of tethered prey. Also, predators usually exhibit feeding periodicity (e.g. diel, tidal, etc.), so mortality risk for prey is rarely a constant through time at any location. The consequences for interpretation of tether losses can be demonstrated using data from Haywood \& Pendrey (1996), who used a chronographic device to record the time at which juvenile penaeid shrimp were removed from tethers by predators in vegetated and unvegetated plots over three $12 \mathrm{~h}$ periods (Fig. 5). The plots in this figure are not total cohort survivorship curves, but represent the temporal distribution of the subset lost (and presumed eaten) in each experimental group. Survival at the end of the experiment was substantially greater in vegetated $(21.9$ and $46.9 \%)$ than in unvegetated plots $(7.1 \%)$, but the point to be made here is that loss rates were not constant in any of the habitat types. Most of the mor- 


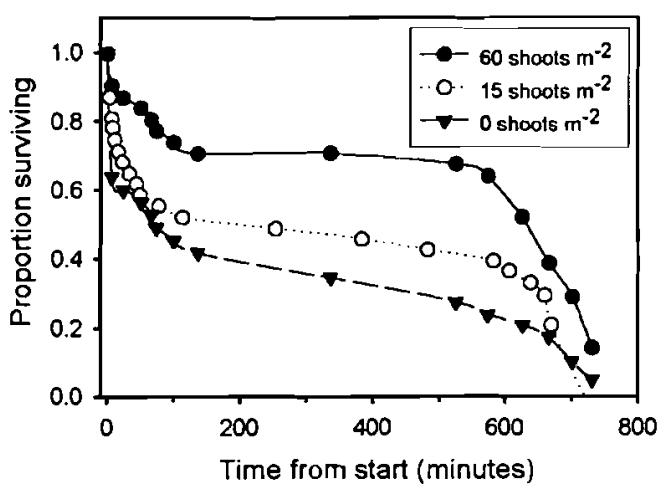

Fig. 5. Penaeus semisulcatus. Survival distributions for groups of tethered penaeid shrimp consumed in experimental plots containing 3 different densities of artificial seagrass shoots. Data were derived from Fig. 3 in Haywood \& Pendrey (1996) using SigmaScan Pro (version 4.0) image analysis software (SPSS, Inc., Chicago, IL, USA)

tality occurred in 2 distinct time periods. The first was immediately after tethered prey were placed in the field at dusk (17:00 to 19:00 h) and lasted about $2.5 \mathrm{~h}$. This phase was followed by a period of about $6.5 \mathrm{~h}$ in which few shrimp were lost from any plot. Then between 02:00 and 04:00 $\mathrm{h}$ loss rates increased substantially. At the end of the $12 \mathrm{~h}$ period, total survival and mean survival time were lowest in the unvegetated plots, leading to the conclusion that relative predation rates were greater in unvegetated habitats. However, it would appear that the time at which one chose to begin and end such an experiment could determine its outcome. At dusk, loss rates (slopes of survival curves) were greater in areas with both 0 and 15 shoots $\mathrm{m}^{-2}$ of artificial vegetation than in the plots with the highest vegetation density, suggesting lower mortality rates in the dense vegetation. Between 150 and $600 \mathrm{~min}$ after the start of the experiment, the slopes of the curves were similar in all experimental plots, suggesting no difference in loss rates among habitats. Near dawn (600 to 800 min after the start), the rate of loss seemed substantially greater in the densest vegetation 60 shoots $\mathrm{m}^{-2}$ ), which would reverse the original conclusion regarding the value of vegetation as a refuge. One might wonder if total survivorship after $12 \mathrm{~h}$ would have been lowest in the dense vegetation had the experiment been initiated near dawn instead of dusk.

If tether losses are used in any quantitative sense to compare spatial or temporal variation in either absolute or relative predation mortality rates, one might wish to consider the sensitivity of the method to resolve such differences. Under the controlled conditions of our experimental manipulation, few statistically significant differences in survival could be distinguished for either free or tethered prey (Table 4). Among treatments with predators, there were no statistically detectable differences in survival of free prey, though losses from the highest density treatment (12 predators $\mathrm{m}^{-2}$ ) were demonstrably greater than in the absence of predators. Most ( $\geq 85 \%$ ) of the free prey survived to the end of the experiment and it is possible that with longer exposure times more differences could have developed, but losses occurred so rapidly within the tethered group that little potential remained for detecting additional differences among treatments above a predator density of 3 ind. $\mathrm{m}^{-2}$. Our findings suggested detection of presence or absence of predators was a realistic expectation of the tethering approach (e.g. Stokesbury \& Himmelman 1995), but differences on a finer scale should not be anticipated.

Under the controlled conditions of our experiment, the expected rank order of both tethered and free prey losses was preserved along the predation gradient and losses within a prey group could be used for ad hoc estimates of predator density at any given time (15 to $180 \mathrm{~min}$ ). A relationship between predation potential and loss rates for each group can be demonstrated, but relative losses in one group do not reliably predict those in the other. Relative losses of tethered prey did not track the relative losses of free prey along the same gradient of predation potential, even though both prey groups were available to the same predators. Nor was there evidence of a compensatory increase in consumption of free prey beyond the point in the gradient of predation potential ( $\geq 3$ ind. $\mathrm{m}^{-2}$ ) where tethered prey were depleted (Fig. 2). Tethered and free grass shrimp responded as if they were different prey species.

Despite the numerous problems associated with tethering, the approach seems to endure largely because it is a simple and intuitively appealing option for addressing the seemingly intractable issue of estimating spatial and temporal patterns of predator effects in open marine systems. We believe that ease of application and lack of alternative methods for quickly assessing risk of mortality due to predators are poor reasons to continue the use of a technique that does not perform as expected. Our findings challenged a fundamental assumption of the tethering approach and demonstrated, at least for this particular predator-prey pair, that it cannot be used as a measure of relative predation losses in free prey.

Acknowledgements. Financial support for participation by C.E.H.S. in this research came from the University of Georgia Marine Institute Student Intern Program. Additional support for the research was provided by a grant to R.T.K. from the National Science Foundation (DEB-9629921). We thank J. P. Kneib, C. C. McIvor and D. Talley, and 4 anonymous reviewers for thought-provoking and critical comments that helped improve an earlier draft of the manuscript. This paper is Contribution Number 846 of the University of Georgia Marine Institute. 


\section{LITERATURE CITED}

Aronson RB (1989) Brittlestar beds: low-predation anachronisms in the British Isles. Ecology 70:856-865

Aronson RB, Heck KL (1995) Tethering experiments and hypothesis testing in ecology. Mar Ecol Prog Ser 121: 307-309

Arsenault DJ, Himmelman JH (1996) Size-related changes in vulnerability to predators and spatial refuge use by juvenile Iceland scallops Chlamys islandica. Mar Ecol Prog Ser 140:115-122

Barbeau MA, Scheibling RE (1994) Procedural effects of prey tethering experiments: predation of juvenile scallops by crabs and sea stars. Mar Ecol Prog Ser 111:305-310

Barshaw DE, Able KW (1990) Tethering as a technique for assessing predation rates in different habitats: an evaluation using juvenile lobsters Homarus americanus. Fish Bull US 88(2):415-417

Beck MW (1995) Size-specific shelter limitation in stone crabs: a test of the demographic bottleneck hypothesis. Ecology 76(3):968-980

Bologna PAX, Heck KL Jr (1999) Differential predation and growth rates of bay scallops within a seagrass habitat. J Exp Mar Biol Ecol 239:299-314

Curran MC, Able KW (1998) The value of tethering fishes (winter flounder and tautog) as a tool for assessing predation rates. Mar Ecol Prog Ser 163:45-51

Haywood MDE, Pendrey RC (1996) A new design for a submersible chronographic tethering device to record predation in different habitats. Mar Ecol Prog Ser 143: 307-312

Heck KL, Thoman TA (1981) Experiments on predator-prey interactions in vegetated aquatic habitats. J Exp Mar Biol Ecol 53:125-134

Heck KL, Valentine JF (1995) Sea urchin herbivory: evidence for long-lasting effects in subtropical seagrass meadows. J Exp Mar Biol Ecol 189:205-217

Heck KL Jr, Wilson KA (1987) Predation rates on decapod crustaceans in latitudinally separated seagrass communities: a study of spatial and temporal variation using tethering techniques. J Exp Mar Biol Ecol 107:87-100

Herrnkind WF, Butler MJ IV (1986) Factors regulating postlarval settlement and juvenile microhabitat use by spiny lobsters Panulirus argus. Mar Ecol Prog Ser 34:23-30

Kneib RT (1995) Behaviour separates potential and realized effects of decapod crustaceans in salt marsh communities. J Exp Mar Biol Ecol 193:239-256

Kneib RT (1997) The role of tidal marshes in the ecology of estuarine nekton. Oceanogr Mar Biol Annu Rev 35:163-220

Lincoln RJ, Boxshall GA, Clark PF (1982) A dictionary of ecology, evolution and systematics. Cambridge University Press, Cambridge

Mansour RA, Lipcius RN (1991) Density-dependent foraging and mutual interference in blue crabs preying upon infaunal clams. Mar Ecol Prog Ser 72:239-246

McClanahan TR, Shafir SH (1990) Causes and consequences of sea urchin abundance and diversity in Kenyan coral reef lagoons. Oecologia 83:362-370

McGuinness KA (1997) Tests for artifact in some methods

Editorial responsibility: Otto Kinne (Editor),

Oldendorf/Luhe, Germany used to study herbivory and predation in mangrove forests. Mar Ecol Prog Ser 153:37-44

McIvor CC, Odum WE (1988) Food, predation risk, and microhabitat selection in a marsh fish assemblage. Ecology 69 : $1341-1351$

Meredith WH, Lotrich VA (1979) Production dynamics of a tidal creek population of Fundulus heteroclitus (Linnaeus). Estuar Coast Mar Sci 8:99-118

Micheli F (1996) Predation intensity in estuarine soft bottoms: between-habitat comparisons and experimental artifacts. Mar Ecol Prog Ser 141:295-302

Minello TJ (1993) Chronographic tethering: a technique for measuring prey survival time and testing predation pressure in aquatic habitats. Mar Ecol Prog Ser 101:99-104

Moksnes PO, Lipcius RN, Pihl L, van Montfrons J (1997) Cannibal-prey dynamics in young juveniles and postlarvae of the blue crab. J Exp Mar Biol Ecol 215:157-187

Nixon SW, Oviatt CA (1973) Ecology of a New England salt marsh. Ecol Monogr 43:463-498

Peterson CH, Black R (1994) An experimentalist's challenge: when artifacts of intervention interact with treatments. Mar Ecol Prog Ser 111:289-297

Peterson CH, Summerson HC, Fegley SR, Prescott RC (1989) Timing, intensity and sources of autumn mortality of adult bay scallops Argopecten irradians concentricus Say. J Exp Mar Biol Ecol 127:121-140

Shulman MJ (1985) Recruitment of coral reef fishes: effects of distribution of predators and shelter. Ecology 66:1056-1066

Sikora WB (1977) The ecology of Palaemonetes pugio in a southeastern salt marsh ecosystem with particular emphasis on production and trophic relationships. PhD thesis. University of South Carolina, Columbia

Smith LD (1995) Effects of limb autotomy and tethering on juvenile blue crab survival from cannibalism. Mar Ecol Prog Ser 116:65-74

Sokal RR, Rohlf FJ (1997) Biometry: the principles and practice of statistics in biological research, 3rd edn. WH Freeman and $\mathrm{Co}$, New York

Stokesbury KDE, Himmelman JH (1995) Biological and physical variables associated with aggregations of the giant scallop Placopecten magellanicus. Can J Fish Aquat Sci 52:743- 753

Valiela I, Wright JE, Teal JM, Volkmann SB (1977) Growth, production and energy transformations in the salt-marsh killifish Fundulus heteroclitus. Mar Biol 40:135-144

Wahle RA, Steneck RS (1992) Habitat restrictions in early benthic life: experiments on habitat selection and in situ predation with the American lobster. J Exp Mar Biol Ecol 157:91-114

Wilson KA (1989) Ecology of mangrove crabs: predation, physical factors and refuges. Bull Mar Sci 44:263-273

Wood CE (1967) Physioecology of the grass shrimp, Palaemonetes pugio, in the Galveston Bay estuarine system. Contrib Mar Sci 12:54-79

Zar JH (1996) Biostatistical analysis, 3rd edn. Prentice Hall, Upper Saddle River, NJ

Zimmer-Faust RK, Fielder DR, Heck KL Jr, Coen LD, Morgan SG (1994) Effects of tethering on predatory escape by juvenile blue crabs. Mar Ecol Prog Ser 111:299-303

Submitted: June 25, 1999; Accepted: March 17, 2000

Proofs received from author(s): April 27, 2000 